\title{
Comparison of ozone retrievals from the Pandora spectrometer system and Dobson spectrophotometer in Boulder, Colorado
}

\author{
J. Herman ${ }^{1}$, R. Evans ${ }^{2}$, A. Cede ${ }^{4}$, N. Abuhassan ${ }^{1}$, I. Petropavlovskikh ${ }^{3}$, and G. McConville ${ }^{3}$ \\ ${ }^{1}$ University of Maryland Baltimore County UMBC-JCET Joint Center for Earth Systems and Technology and \\ NASA Goddard Space Flight Center Greenbelt, Greenbelt, MD 20771, USA \\ ${ }^{2}$ NOAA Earth System Research Laboratory, 325 Broadway, Boulder, CO 80305, USA \\ ${ }^{3}$ Cooperative Institute for Research in Environmental Sciences, University of Colorado, Boulder 80309, USA \\ ${ }^{4}$ Goddard Earth Sciences Technology \& Research (GESTAR) Columbia, Columbia, MD 21046, USA \\ Correspondence to: J. Herman (jay.r.herman@ nasa.gov)
}

Received: 20 January 2015 - Published in Atmos. Meas. Tech. Discuss.: 20 March 2015

Revised: 2 July 2015 - Accepted: 7 July 2015 - Published: 24 August 2015

\begin{abstract}
A comparison of retrieved total column ozone (TCO) amounts between the Pandora \#34 spectrometer system and the Dobson \#061 spectrophotometer from directsun observations was performed on the roof of the Boulder, Colorado, NOAA building. This paper, part of an ongoing study, covers a 1-year period starting on 17 December 2013. Both the standard Dobson and Pandora TCO retrievals required a correction, TCOcorr $=\mathrm{TCO}(1+C(T))$, using a monthly varying effective ozone temperature, $T_{\mathrm{E}}$, derived from a temperature and ozone profile climatology. The correction is used to remove a seasonal difference caused by using a fixed temperature in each retrieval algorithm. The respective corrections $C\left(T_{\mathrm{E}}\right)$ are $C_{\text {Pandora }}=0.00333\left(T_{\mathrm{E}}-225\right)$ and $C_{\text {Dobson }}=-0.0013\left(T_{\mathrm{E}}-226.7\right)$ per degree $\mathrm{K}$. After the applied corrections removed most of the seasonal retrieval dependence on ozone temperature, TCO agreement between the instruments was within $1 \%$ for clear-sky conditions. For clear-sky observations, both co-located instruments tracked the day-to-day variation in total column ozone amounts with a correlation of $r^{2}=0.97$ and an average offset of $1.1 \pm 5.8$ DU. In addition, the Pandora TCO data showed $0.3 \%$ annual average agreement with satellite overpass data from AURA/OMI (Ozone Monitoring Instrument) and 1\% annual average offset with Suomi-NPP/OMPS (Suomi National Polar-orbiting Partnership, the nadir viewing portion of the Ozone Mapper Profiler Suite).
\end{abstract}

1 Description of ground-based instruments (PANDORA spectrometer system and Dobson spectrophotometer)

This paper compares ground-based total column ozone (TCO) retrievals obtained by two very different technologies: (1) the Dobson \#061 spectrophotometer is designed to utilize a spectral differential absorption technique by making measurements of solar ultra violet radiation through a pair of spectrally separated slits, and (2) the Pandora \#34 spectrometer system TCO algorithm is based on spectral fitting, 305-330 nm, of the attenuated solar spectrum using a modern small symmetric Czerny-Turner design spectrometer. For validation purposes, Pandora TCO is further compared with satellite-retrieved TCO overpass data over Boulder, Colorado.

The Dobson spectrophotometer was developed in the mid1920s to measure stratospheric ozone and to assist investigations of atmospheric circulation (Dobson, 1957, 1968). The Dobson time series of TCO measurements date back as far as 1926 for the Arosa, Switzerland, station. Knowledge of global stratospheric ozone levels prior to satellite instruments is based primarily on measurements with these instruments (Dobson, 1957, 1968). A world-wide network was developed after the instrument redesign in 1947 and the International Geophysical Year in 1957. Measurements made with the Dobson spectrophotometer can be analyzed for total column content of ozone or for ozone vertical profiles (Umkehr technique, Mateer and DeLuisi, 1992), depending 
on the light source observed (direct-sun or sky radiances). The Dobson instrument calibration uses the "classical" Langley plot method to determine an effective extraterrestrial solar constant (Langley, 1884; Shaw, 2007), which is unique to each instrument.

A complete description of the Dobson operation, principles of measurement, and use is available elsewhere (Evans and Komhyr, 2008). Briefly, the instrument measures the difference between the intensity of selected wavelength pairs in the range $300-340 \mathrm{~nm}$ (Eq. 1).

A - pair (A1 : 305.5/A2:325.0nm)

$\mathrm{C}$ - pair $(\mathrm{C} 1: 311.5 / \mathrm{C} 2: 332.4 \mathrm{~nm})$

D - pair (D1 : 317.5/D2:339.9nm)

A spectrum is produced by a prism spectrograph and projected onto a slit board containing two slits $S_{2}$ and $S_{3}$, with the intensity of the longer wavelength at $S_{3}$ being stronger than that at $S_{2}$, since light at $S_{2}$ is more strongly absorbed by ozone. A calibrated variable neutral density filter ("attenuator") is used to reduce the intensity of the stronger wavelength $\left(S_{3}\right)$ to that of the weaker $\left(S_{2}\right)$. The light from the two slits is collected in a photomultiplier tube (PMT); the current is amplified and differenced in an external meter so that when the intensities from the slits are equal at the PMT; the meter reads 0 . During the measurement, the variability in the PMT readings is recorded and used as a quality control of the measurements and to detect optically thin clouds.

A measurement with the Dobson spectrophotometer with a defined wavelength pair (A, C, or D) is recorded as the position of the attenuator when the meter reads 0 . When the instrumental extraterrestrial constant $\left(I_{\text {ETC }}\right)$ is combined with the measurement $I_{\text {meas }}$, the result is then expressed as an $N$ value. Based on Beer's Law, an $N$ value is defined as (Eq. 2)

$$
\begin{aligned}
\mathrm{N} & =\log \left[I_{\mathrm{ETC}}\left(S_{2}\right) / I_{\mathrm{ETC}}\left(S_{3}\right)\right] \\
& -\log \left[I_{\text {meas }}\left(S_{2}\right) / I_{\text {meas }}\left(S_{3}\right)\right],
\end{aligned}
$$

where $N$ is the relative logarithmic attenuation caused by ozone and aerosols for the wavelength pair. The $N$ values are converted to TCO values through the use of standardized effective ozone cross sections and Rayleigh scattering optical depths determined through convolution with the standard Dobson spectral band passes (Komhyr et al., 1993).

For normal measurements designed to determine the total column content of ozone, the measurements are taken using multiple pairs $(\mathrm{A}+\mathrm{D}$ or $\mathrm{C}+\mathrm{D})$, combined to minimize the effects of aerosols and other absorbers, and corrected for Rayleigh scattering. The standard retrieval algorithm uses ozone absorption coefficients determined from the Bass and Paur (Bass and Paur, 1985) laboratory measurements of the ozone cross section. The standard effective ozone cross sections are applied to process measurements at all Dobson stations at a fixed effective stratospheric temper- ature of $T_{\mathrm{E}}=-46.3^{\circ} \mathrm{C}$. This is known to produce a systematic error in retrieved TCO caused by seasonal and meridional variability in stratospheric temperatures (Redondas et al., 2014).

Dobson instrument calibrations are maintained by comparison with the World Standard Dobson \#083, which is carefully maintained with regular Langley plot calibration at the Mauna Loa Observatory in Hawaii by NOAA's Earth System Research Laboratory (Boulder, CO). The Boulder station instrument, Dobson \#061, is formally compared to Dobson \#083 approximately once a year since 1982. Informal (without time synchronization) comparisons were also performed at various occasions whenever Dobson \#083 was operated in Boulder. The calibration of Dobson \#061 is changed to match Dobson \#083 only when the results of the intercomparison are consistently different by more than $1 \%$. Over the last 5 years, the difference between total column ozone derived from these two instruments was found to be within $\pm 1 \%$ for air masses smaller than 2.5 when using the AD-DSGQP type measurement (A-D pair wavelengths direct sun using a ground quartz plate for clear-sky conditions). Based on the last two formal intercomparisons (2013 and 2014), Dobson \#061 results are estimated to be $0.5 \% \pm 1 \%$ lower than Dobson \#083 results.

Recently, a small spectrometer system designed to measure atmospheric trace gases, Pandora, has become available based on commercial spectrometers with the stability and stray light characteristics that make them suitable candidates for direct-sun measurements of total columns of ozone and other trace gases in the atmosphere (Herman et al., 2009; Tzortziou et al., 2012). Sky observations are also made for deriving trace gas altitude profiles. The Pandora spectrometer system uses a temperature-stabilized $\left(1^{\circ} \mathrm{C}\right)$ symmetric Czerny-Turner system from Avantes over the range 280$525 \mathrm{~nm}(0.6 \mathrm{~nm}$ resolution with $4.5 \times$ oversampling $)$ with $2048 \times 64$ back-thinned Hamamatsu CCD, 50 micron entrance slit, and 1200 lines per mm grating and is fed light by a 400 micron core diameter fiber optic cable. The fiber optic cable obtains light from the sun, moon, or sky from frontend optics with a $2.2^{\circ}$ field of view (FOV) for direct-sun observations using a diffuser and $1.6^{\circ}$ FOV for sky observations without a diffuser. The optical head uses a double filter wheel containing four neutral density filters, a UV340 filter, ground-fused silica diffusers, and a blocked position. When combined with the variable exposure time (4-4000 ms), Pandora has a dynamic range of $10^{7}$ to 1 , which is sufficient for viewing both direct sun and sky and for measuring the dark current in between each measurement. Wavelength calibration is performed at several spectrometer temperatures using a variety of narrow line emission lamps that cover most of the spectral range $280-525 \mathrm{~nm}$. From the laboratory data, a polynomial is fitted to the results as a function of pixel column number 1-2048. Wavelength calibration was validated using comparisons with the slit function convolved high-resolution Kurucz spectrum's solar Fraunhofer lines. Based on labora- 
tory measurements, the Avantes spectrometers are corrected for response nonlinearity to the incoming signal, which can amount to $3 \%$ at high counts and is negligible at low counts. The exposure times to sun or sky photons are adjusted so that the readout pixel with the highest intensity is never in excess of $80 \%$ of the CCD readout well depth of 200000 electrons. This means that each pixel in the 64 rows for each wavelength is limited to less than 2500 electrons. The laboratorycalibrated Pandora TCO retrieval algorithm uses an external solar reference spectrum derived from a combination of the Kurucz spectrum (wavelength resolution $\lambda / \Delta \lambda=500000$ ) radiometrically normalized to the lower-resolution shuttle Atlas-3 SUSIM spectrum (Van Hoosier, 1996; Bernhard et al., 2004). Ozone absorption cross sections (BDM) are from Brion et al. (1993, 1998) and Malicet et al. (1995). The use of a well-calibrated top-of-the-atmosphere spectrum convolved with the laboratory-measured spectrometer slit function derived for each pixel permits derivation of ozone amounts without resorting to either a Langley calibration approach or calibration transfer from a standard instrument. The core slit function is known to within $1 \%$, which propagates into an ozone error of less than $1 \%$.

The Pandora system has been tested in the laboratory to determine the impact of the stray light in 300-330 nm spectral range (Tzortziou et al., 2012). The study found that Pandora stray light $\left(10^{-5}\right)$ is comparable to a single grating Brewer spectrometer. The use of a UV340 filter removes most of the stray light that originates from wavelengths longer than $380 \mathrm{~nm}$. A typical UV340 filter has a small leakage $(5 \%)$ in the vicinity of $720 \mathrm{~nm}$, which misses the detector and hits the internal baffles. A very small, but unknown, amount of this stray light may scatter on to the detector. The "dark pixel" method correction is then applied to remove remaining stray light, which allows ozone retrievals to be accurate up to a slant column between 1400 and 1500 DU or 70 and $80^{\circ}$ solar zenith angles (SZAs), depending on the TCO amount.

An empirical measure of uncorrected stray light is obtained by examining the retrieved TCO as a function of air mass. If there is residual uncorrected stray light, then the retrieved TCO will be curved downward from noon (inverted U shape) with increasing air mass. This is especially evident on days when TCO is nearly constant throughout the day. It is also evident at very large air masses, when the signal is almost all stray light (no UV), and the retrieved TCO incorrectly decreases rapidly near sunrise and sunset. For certain older spectrometers that happen to have an unexpectedly large amount of stray light, a stray light correction as a function of air mass is applied so that days with nearly constant TCO have no retrieved curvature.

The Boulder, Colorado, Pandora \#34 uses an older model of the Avantes spectrometer that has more stray light than the newer models with improved baffling. The excess stray light resulted in observed curvature of TCO vs. time of day centered about noon. To correct this, we used the following empirical stray light correction equation.

$$
\begin{aligned}
\mathrm{O}_{3}(\text { Corrected })= & \mathrm{O}_{3}(\text { Measured }) \\
& {\left[1+0.066 \mathrm{AMF}^{0.4}-19.0\right] }
\end{aligned}
$$

where the air-mass factor (AMF) is approximately equal to $1 / \cos (\mathrm{SZA})$ for direct-sun measurements. This completely removed the noon-centered curvature. For typical TCO values in Boulder, the correction permits good retrievals out to SZAs greater than $70^{\circ}$.

The algorithm for deriving ozone amounts differs from Dobson or Brewer instruments in that spectral fitting is used to cover the entire 310 to $330 \mathrm{~nm}$ range with a weighting system that measures the noise as a function of wavelength for each single pixel and inversely weights the significance of the fitting to the amount of noise. On a typical clear-sky day, about 4000 direct-sun measurements are taken in $20 \mathrm{~s}$ at low to moderate SZAs. The 4000 measurements are broken into small groups that are averaged together, and their standard deviation is determined. Averaging improves the single measurement signal-to-noise ratio (SNR) by a factor of 60 , and the standard deviation from the mean provides the inverse weighting.

The effective signal-to-noise ratio is composed of a combination of electron noise and readout noise. For pixels having the maximum intensity, the exposure time is adjusted automatically to $80 \%$ readout well depth filling $(80 \%$ of 200000 electrons or an electron signal-to-noise ratio greater than $400: 1$ ). The electron signal-to-noise ratio at the $\mathrm{O}_{3}$ absorption wavelengths is less (about 40000 electrons) or about 200 : 1. Averaging 4000 measurements gives an increase of a factor of 60, or an SNR of $12000: 1$. In addition, the spectrometer is better than 4 times over sampled (more than four pixels per $0.5 \mathrm{~nm}$ ), which gives another factor of 2. Finally, we use a $20 \mathrm{~nm}$ band for the spectral fitting, which further increases the signal-to-noise ratio. Other noise signals in the Pandora system and in the changing atmosphere are larger. On days when $\mathrm{O}_{3}$ is nearly constant, the low instrument noise is evident in the very low retrieved ozone scatter between successively retrieved $\mathrm{O}_{3}$ values. For all conditions, the optimum exposure time is determined using a test exposure just prior to the $20 \mathrm{~s}$ measuring period, which can range from 4 $\mathrm{ms}$ to $4 \mathrm{~s}$. The linearity of the spectrometer system has been determined over the entire range of exposure times used in the measurements.

An estimate of TCO retrieval precision and standard deviation can be obtained from a similar Pandora located at Mauna Loa Observatory where the geophysical ozone variability is at a minimum compared to other sites. On a quiet cloud-free day (1 February 2015) the ozone value was $236.27 \pm 0.35 \mathrm{DU}$ for 77 values between 11:00 and 13:00 h. Some of this variation, $0.15 \%$, is natural TCO variability and some is from instrument noise. If we assume that the entire variability is instrument noise, the signal-to-noise ratio would be $650: 1$. From a spectral fitting viewpoint, the 
Mauna Loa estimated ozone error is $0.069 \pm 0.0016 \mathrm{DU}$, or about $0.029 \%$, which gives an SNR of about 3500 : 1 . This estimate includes both total instrument noise and spectral fitting errors. The estimated SNR will decrease with increasing AMF and with cloud cover. The conclusion is that the Pandora spectrometer system is not noise limited when measuring under clear-sky conditions.

TCO retrievals can be made under moderately cloudy conditions and at high SZA, but with increasing noise level because decreased UV sunlight reduces the number of measurements possible in $20 \mathrm{~s}$ while continuing to fill the CCD readout well to about $80 \%$. Aerosols without spectral absorption features have little effect on the TCO value retrieved and are mostly removed by use of a fourth-order polynomial in the retrieval algorithm. Both clouds and aerosols increase the retrieved TCO amount slightly because of multiple scattering within the cloud or aerosol layer.

Thick clouds reduce the number of available photons to the point where practical measurements are not possible because of decreased SNR. Since Pandora also measures total column $\mathrm{NO}_{2}$ amounts using visible wavelengths (400-440 nm), a second cycle of measurements lasting $20 \mathrm{~s}$ is used without the UV340 filter. The result is that TCO is measured every $80 \mathrm{~s}$, since each $20 \mathrm{~s}$ measurement with light input is followed by $20 \mathrm{~s}$ of dark count measurements with the same exposure time.

The algorithms and calibration techniques for the Dobson spectrophotometer (Komhyr and Evans, 2006) are carefully documented in available documents or open literature. Documentation for Pandora, PanSoftwareSuite1.5_Manual.pdf, is available at http://avdc.gsfc.nasa.gov/pub/tools/Pandora/ install, with a detailed description in http://avdc.gsfc. nasa.gov/pub/DSCOVR/Pandora/Web, and in Herman et al. (2009).

The retrieved Pandora TCO amounts have also been successfully compared to a carefully calibrated double grating Brewer spectrometer \#171 (Tzortziou et al., 2012) that uses a six-wavelength algorithm based on the $\mathrm{BDM} \mathrm{O}_{3}$ cross sections (an improvement over the standard four-wavelength method) as described by Cede and Herman (2005). The key results show good correlation between the Pandora and Brewer TCO amounts, even at high SZA, but with a clear seasonal difference caused by the assumption of a constant effective stratospheric temperature for the ozone absorption cross section, $225^{\circ} \mathrm{K}$, in the Pandora algorithm. The Brewer ozone retrieval wavelengths were selected to minimize the retrieval temperature sensitivity effect.

This paper will focus on 1 year's worth of data collected to perform direct comparison between the Dobson instrument (\#061) in Boulder, Colorado, located on the roof of the NOAA building and a Pandora (\#34) adjacently located since 17 December 2013. All of the Dobson TCO comparisons in the following sections use retrieved clear-sky ADDSGQP. The Pandora-retrieved TCO data are matched to the Dobson AD-DSGQP data times $t_{\mathrm{o}}$ and averaged over the in-

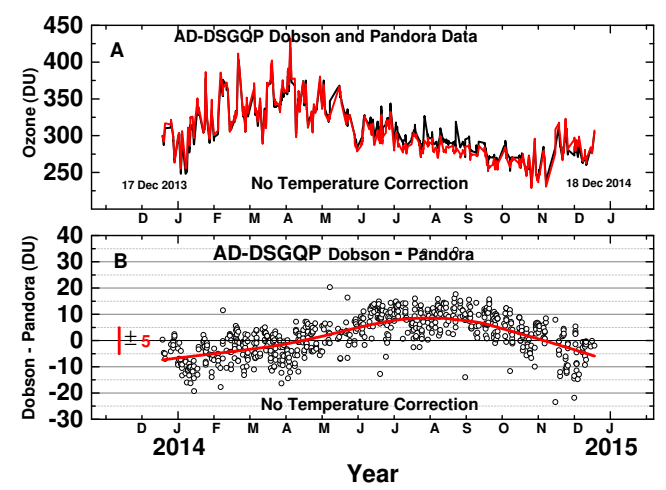

Figure 1. (a) Retrieved AD-DSGQP TCO data obtained from Dobson \#061 and Pandora \#34 atop the NOAA building in Boulder, Colorado, for $\pm 8 \mathrm{~min}$ average of $\mathrm{TCO}(\mathrm{Pan})$ about the Dobson measurement time. (b) The difference TCO(Dobson) - TCO(Pandora), showing a change in bias as a function of season without temperature correction. The standard deviation from the red Lowess (0.5) curve is \pm 5 DU. In this and subsequent graphs, the abscissa labels are for the first day of each month from 1 December 2013 to 1 January 2015.

terval $t_{\mathrm{o}} \pm 8 \mathrm{~min}$. Temperature corrections are applied based on a standard temperature and ozone climatologies appropriate for $40^{\circ} \mathrm{N}$ (see next section). A future paper will discuss Pandora-retrieved $T_{\mathrm{E}}$ compared with $T_{\mathrm{E}}$ derived from balloon sonde temperature profiles and their effect on retrieved TCO.

\section{TCO: Dobson spectrophotometer \#061 compared with Pandora spectrometer \#34}

Both Pandora and Dobson ozone column retrievals depend on the choice of the spectroscopic ozone absorption data sets, their spectral temperature dependence, and selection of the stratospheric effective temperature $T_{\mathrm{E}}$ for daily data processing. The current Pandora spectral fitting algorithm uses BDM ozone cross sections, while the standard Dobson wavelength pair algorithm uses Bass and Paur ozone cross sections (Bass and Paur, 1985). The standard retrieval algorithms for both instruments use fixed effective TCO retrieval temperatures (Dobson: $226.7^{\circ} \mathrm{K}$ and Pandora: $225^{\circ} \mathrm{K}$ ), even though there is known seasonal variation in stratospheric temperature. A comparison of Pandora TCO with Dobson TCO shows that the two instruments track the daily ozone amounts equally well (Fig. 1).

Figure 1a shows TCO data uncorrected for temperature from 17 December 2013 to 18 December 2014. The difference TCO(Dobson) - TCO(Pandora) shows a seasonal dependence (Fig. 1b) that appears to approximately track the seasonal change in stratospheric ozone weighted effective temperature (Table 1 and Fig. 2). The difference between the two time-matched data sets (Fig. 1b) shows that the net difference in temperature sensitivity causes a small systematic seasonal difference between Pandora and the Dobson spec- 
Table 1. Ozone weighted average effective temperature $T_{\mathrm{E}}\left({ }^{\circ} \mathrm{K}\right)$ vs. ozone amount (DU) and month appropriate for Boulder, Colorado.

\begin{tabular}{lrrrrrrrr}
\hline Mon/TCO & $225 \mathrm{DU}$ & $275 \mathrm{DU}$ & $325 \mathrm{DU}$ & $375 \mathrm{DU}$ & $425 \mathrm{DU}$ & $475 \mathrm{DU}$ & $525 \mathrm{DU}$ & $575 \mathrm{DU}$ \\
\hline Jan & 224.2 & 223.2 & 222.5 & 221.9 & 221.4 & 221.0 & 220.7 & 220.4 \\
Feb & 225.6 & 224.5 & 223.6 & 222.9 & 222.3 & 221.9 & 221.5 & 221.2 \\
Mar & 226.9 & 225.6 & 224.6 & 223.8 & 223.1 & 222.6 & 222.1 & 221.7 \\
Apr & 229.5 & 228.0 & 226.7 & 225.7 & 224.8 & 224.1 & 223.5 & 223.0 \\
May & 232.7 & 230.9 & 229.4 & 228.1 & 227.0 & 226.1 & 225.3 & 224.5 \\
Jun & 235.0 & 233.0 & 231.4 & 229.8 & 228.5 & 227.5 & 226.6 & 225.9 \\
Jul & 235.1 & 233.3 & 231.6 & 230.0 & 228.7 & 227.6 & 226.7 & 225.9 \\
Aug & 234.0 & 232.1 & 230.3 & 228.8 & 227.6 & 226.6 & 225.8 & 225.2 \\
Sep & 230.6 & 229.1 & 227.6 & 226.4 & 225.4 & 224.5 & 223.8 & 223.2 \\
Oct & 226.5 & 225.2 & 224.0 & 222.9 & 222.1 & 221.5 & 221.1 & 220.7 \\
Nov & 223.3 & 222.2 & 221.4 & 220.8 & 220.3 & 219.8 & 219.4 & 219.1 \\
Dec & 222.8 & 221.9 & 221.1 & 220.6 & 220.1 & 219.7 & 219.4 & 219.1 \\
\hline
\end{tabular}

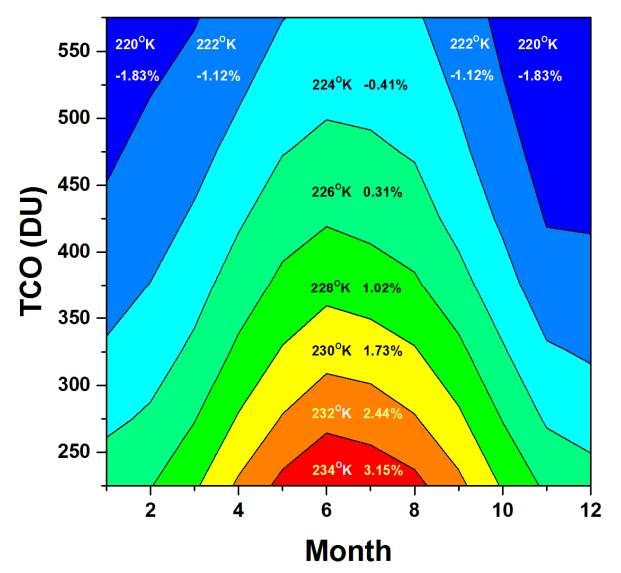

Figure 2. Ozone effective weighted temperatures $T(\mathrm{OK})$ and the percent Pandora ozone correction function $C(T)$ (in \%) based on a fixed retrieval temperature of $225 \mathrm{OK}$ for the latitude of Boulder, Colorado, at $40^{\circ} \mathrm{N}$ as a function of total column ozone (TCO) amount and month. $C_{\text {Pandora }}=0.00333(T-225)$, where TCOcorr $=$ TCO $(1+C(T))$. The number pairs $(T, C(T))$ represent the average values temperature and percent correction for the colored area, not the contour boundaries.

trophotometers $(-5 \mathrm{DU}$ or $-2 \%$ in winter and $+10 \mathrm{DU}$ or $+3 \%$ in summer). The seasonal difference is significant at the level of 1 standard deviation $\pm 5 \mathrm{DU}$ of the observed data relative to the Lowess(0.5) curve (Fig. 1b). The Lowess $(f)$ procedure is based on local least squares fitting using loworder polynomials applied to a specified fraction, $\mathrm{f}$, of the data (Cleveland and Devlin, 1988).

A compiled climatology of ozone and temperature (Table 1) was used to generate the ozone-weighted effective temperature $T_{\mathrm{E}}$ for the location of Boulder, Colorado, at $40^{\circ} \mathrm{N}$ latitude. The tables are given as a function of latitude and ozone amount for each month (see ftp://toms.gsfc.nasa.gov/ pub/ML_climatology for climatology data files and discussions by Wellemeyer et al., 1997; McPeters et al., 2007;
McPeters and Labow, 2012). For this study, only the monthly data for latitudes of $30-40^{\circ} \mathrm{N}$ and $40-50^{\circ} \mathrm{N}$ are used to form an average suitable for $40^{\circ} \mathrm{N}$. $T_{\mathrm{E}}$ is not an intrinsic function of TCO. However, for a given latitude and month, the ozone profile shape climatology was systematically organized by total column amount, so that the $T_{\mathrm{E}}$ tables can be parameterized by TCO.

All Dobson TCO values for the WMO GAW network (including data from the Boulder Dobson \#061) are derived based on procedures in the Dobson operational manual (Evans and Komhyr, 2008). Temperature sensitivity of the Dobson effective ozone cross sections for direct-sun measurement is based on the Bass and Paur ozone cross-section spectroscopy data set (Bass and Paur, 1985) and respective spectral band passes measured for the Dobson \#083 instrument (Komhyr et al., 1993). Recent analysis (Redondas et al., 2014, and references therein) shows that temperature dependence in the Dobson and Brewer derived total column ozone is based on the choice of the spectroscopic data set, its spectral temperature sensitivity, and specific selection of spectral band passes. Since total column ozone from Dobson \#061 is processed with the Bass and Paur ozone cross sections, we use $-0.13 \%{ }^{\circ} \mathrm{K}^{-1}$ (Komhyr et al., 1993) to correct the results for seasonal variability in stratospheric temperatures over Boulder, CO. Moreover, calculations recently published by Redondas et al. (2014) find very similar temperature sensitivity for Dobson \#083 $\left(-0.133 \%{ }^{\circ} \mathrm{K}^{-1}\right)$ for the Bass and Paur ozone cross-section data set and a different sensitivity using the $\mathrm{BDM} \mathrm{O}_{3}$ cross-section data (see Appendix A).

The temperature dependence for Pandora, $+0.33 \%{ }^{\circ} \mathrm{K}^{-1}$, is determined by applying retrievals at a series of different ozone temperatures from 215 to $240^{\circ} \mathrm{K}$ for the BDM ozone cross sections (see http://satellite.mpic.de/spectral_atlas) and obtaining a linear fit to the percent change. The temperature corrections are shown in Table 2 and Fig. 2. A similar figure could be made for the Dobson instrument based on the data in Table 3. Most of the $\mathrm{O}_{3}$ retrieval temperature sensitivity is as- 
Table 2. Pandora TCO correction in percent as a function of month and ozone amount for $40^{\circ} \mathrm{N}$.

\begin{tabular}{lrrrrrrrr}
\hline Month/TCO & $225 \mathrm{DU}$ & $275 \mathrm{DU}$ & $325 \mathrm{DU}$ & $375 \mathrm{DU}$ & $425 \mathrm{DU}$ & $475 \mathrm{DU}$ & $525 \mathrm{DU}$ & $575 \mathrm{DU}$ \\
\hline Jan & 0.37 & -0.20 & -0.67 & -1.03 & -1.33 & -1.57 & -1.80 & -1.97 \\
Feb & 0.63 & 0.07 & -0.37 & -0.73 & -1.03 & -1.27 & -1.50 & -1.70 \\
Mar & 1.27 & 0.63 & 0.10 & -0.30 & -0.67 & -0.97 & -1.27 & -1.50 \\
Apr & 2.20 & 1.43 & 0.80 & 0.30 & -0.13 & -0.53 & -0.87 & -1.13 \\
May & 3.00 & 2.13 & 1.43 & 0.83 & 0.37 & -0.07 & -0.43 & -0.77 \\
Jun & 3.50 & 2.60 & 1.83 & 1.17 & 0.60 & 0.13 & -0.23 & -0.53 \\
Jul & 3.30 & 2.47 & 1.73 & 1.00 & 0.47 & 0.07 & -0.27 & -0.53 \\
Aug & 3.00 & 2.13 & 1.43 & 0.77 & 0.27 & -0.10 & -0.40 & -0.67 \\
Sep & 2.27 & 1.50 & 0.83 & 0.20 & -0.26 & -0.60 & -0.87 & -1.10 \\
Oct & 1.30 & 0.63 & 0.03 & -0.47 & -0.87 & -1.17 & -1.43 & -1.63 \\
Nov & 0.53 & -0.13 & -0.67 & -1.17 & -1.50 & -1.77 & -1.93 & -2.10 \\
Dec & 0.27 & -0.37 & -0.83 & -1.20 & -1.53 & -1.80 & -2.00 & -2.17 \\
\hline
\end{tabular}

Table 3. Dobson TCO correction in percent as a function of month and ozone amount for $40^{\circ} \mathrm{N}$.

\begin{tabular}{lrrrrrrrr}
\hline Month/TCO & $225 \mathrm{DU}$ & $275 \mathrm{DU}$ & 325 DU & 375 DU & $425 \mathrm{DU}$ & $475 \mathrm{DU}$ & $525 \mathrm{DU}$ & $575 \mathrm{DU}$ \\
\hline Jan & 0.078 & 0.299 & 0.481 & 0.624 & 0.741 & 0.832 & 0.923 & 0.988 \\
Feb & -0.026 & 0.195 & 0.364 & 0.507 & 0.624 & 0.715 & 0.806 & 0.884 \\
Mar & -0.273 & -0.026 & 0.182 & 0.338 & 0.481 & 0.598 & 0.715 & 0.806 \\
Apr & -0.637 & -0.338 & -0.091 & 0.104 & 0.273 & 0.429 & 0.559 & 0.663 \\
May & -0.949 & -0.611 & -0.338 & -0.104 & 0.078 & 0.247 & 0.390 & 0.520 \\
Jun & -1.144 & -0.793 & -0.494 & -0.234 & -0.013 & 0.169 & 0.312 & 0.429 \\
Jul & -1.066 & -0.741 & -0.455 & -0.169 & 0.039 & 0.195 & 0.325 & 0.429 \\
Aug & -0.949 & -0.611 & -0.338 & -0.078 & 0.117 & 0.260 & 0.377 & 0.481 \\
Sep & -0.663 & -0.364 & -0.104 & 0.143 & 0.325 & 0.455 & 0.559 & 0.650 \\
Oct & -0.286 & -0.026 & 0.208 & 0.403 & 0.559 & 0.676 & 0.780 & 0.858 \\
Nov & 0.013 & 0.273 & 0.481 & 0.676 & 0.806 & 0.910 & 0.975 & 1.040 \\
Dec & 0.117 & 0.364 & 0.546 & 0.689 & 0.819 & 0.923 & 1.001 & 1.066 \\
\hline
\end{tabular}

Table 4. Location of OMI and NPP overpass data sets.

\begin{tabular}{ll}
\hline OMI: & http://avdc.gsfc.nasa.gov/index.php?site= \\
& 1593048672\&id=28 \\
NPP: & http://avdc.gsfc.nasa.gov/pub/data/satellite/Suomi_ \\
& NPP/OVP/TC_EDR_TO3/ \\
\hline
\end{tabular}

sociated with Pandora because of the spectral fitting method compared to the pair ratio method for the Dobson.

Applying both respective corrections based on the effective ozone temperatures $T$ (Month,TCO) and Dobson Bass and Paur cross-section retrievals, where TCOcorr $=\mathrm{TCO}$ $\left(1+C\left(T_{\mathrm{E}}, \mathrm{TCO}\right)\right)$, gives the results shown in Fig. 3. After removing the seasonal temperature effect from both Pandora and Dobson TCO retrieval algorithms, the average bias is reduced by a factor of $2(-2.5 \mathrm{DU}$ or $\sim 1 \%$ in winter and $+5 \mathrm{DU}$ or $1.5 \%$ in summer) and is within a standard deviation of $5 \mathrm{DU}$ about the Lowess $(0.5)$ curve. Based on the standard deviation from the mean $(1.1 \pm 5 \mathrm{DU}$ or $\pm 1.7 \%)$, the mean difference of $1.1 \mathrm{DU}$ is statistically not different from 0 . While there is significant scatter for the entire temperature- corrected data set (Fig. 3b), the day-to-day agreement is good, as shown in Fig. 3a. The mean difference, $0.4 \%$, is similar to the mean difference between Dobson \#061 and the Dobson \#083 reference instrument.

The scatterplots (Fig. 4a and b) for Pandora vs. Dobson TCO confirm the high correlation $\left(r^{2}=0.96\right.$ and 0.97$)$ and near agreement (slopes 1.05 and 1.02) of the two data sets. Including the temperature correction for both Dobson and Pandora retrievals almost removes the seasonal bias and improves the correlation and agreement slightly.

\section{Validation: Pandora vs. OMI (Ozone Monitoring Instrument) and NPP satellite overpass TCO}

A similar comparison with Pandora can be made using satellite TCO overpass data from AURA/OMI and from SuomiNPP/OMPS (Suomi National Polar-orbiting Partnership, the nadir viewing portion of the Ozone Mapper Profiler Suite). The data used are derived using the TOMS (Total Ozone Mapping Spectrometer) OMTO3 discrete wavelength algorithm with a temperature correction applied based on a 


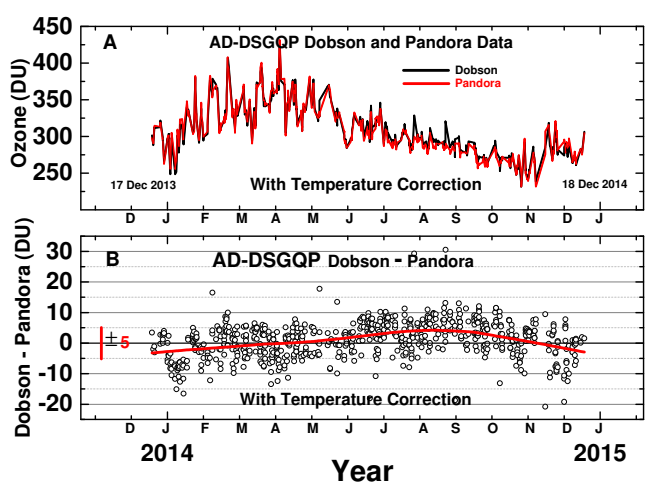

Figure 3. (a) Temperature-corrected retrieved TCO data obtained from the Dobson \#061 instrument and Pandora \#34 spectrometer. (b) The difference TCO(Dobson) - TCO(Pandora) with temperature corrections removing most of the seasonal bias. The standard deviation from the red Lowess(0.5) curve is \pm 5 DU.
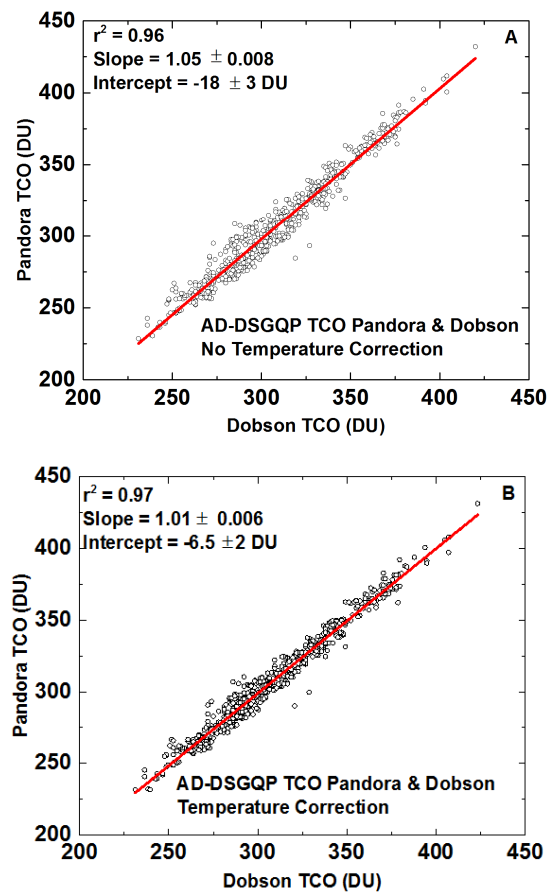

Figure 4. Scatterplot of Pandora TCO vs. Dobson TCO for clearsky AD-DSGQP conditions: (a) no temperature correction and (b) with temperature correction.

monthly zonal mean temperature climatology (Bhartia and Wellemeyer, 2002). The Pandora data are matched to either the OMI or NPP overpass times within $\pm 8 \mathrm{~min}$ and averaged over the 16 min interval (see Figs. 5 and 6). OMI retrievals used the Bass and Paur $\mathrm{O}_{3}$ cross sections and OMPS retrievals used the $\mathrm{BDM} \mathrm{O}_{3}$ cross sections. As with the Dobson retrieval (see Appendix A), use of BDM increases the retrieved OMPS TCO by about $0.6 \%$ compared to the Bass and Paur OMI TCO retrieval.

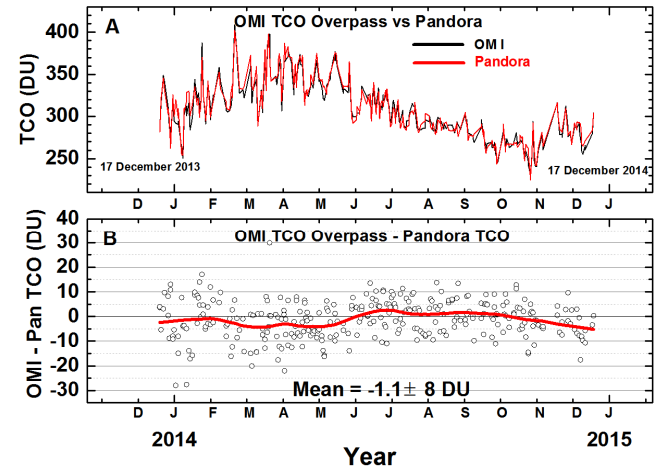

Figure 5. (a) OMI overpass TCO data for Boulder, Colorado, compared to Pandora TCO data averaged over a 16 min interval centered on the OMI overpass time. (b) OMI TCO - Pandora TCO and a Lowess(0.2) fit (red curve).

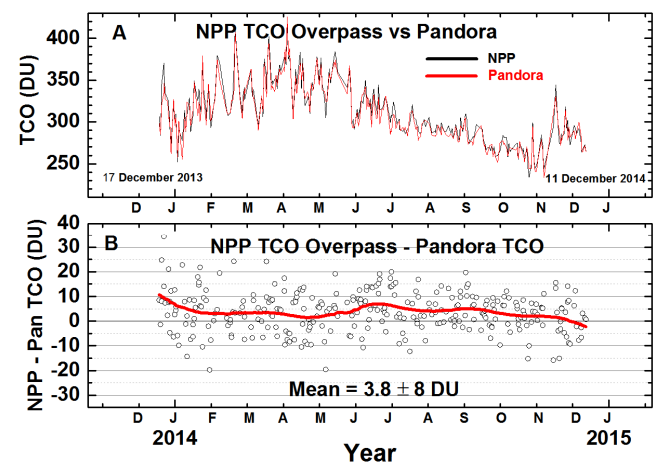

Figure 6. (a) NPP overpass TCO data for Boulder, Colorado, compared to Pandora TCO data averaged over a 16 min interval centered on the OMI overpass time. (b) OMI TCO - Pandora TCO and a Lowess(0.2) fit (red curve).

Temperature-corrected Pandora ozone compared to the OMI TCO overpass data set (Fig. 5) shows no seasonal bias and has a mean difference of $1.1 \pm 8 \mathrm{DU}$. A similar comparison between Pandora and Suomi NPP/OMPS TCO overpass data (Fig. 6) shows an average offset of $3.8 \pm 8$ DU. For both OMI and NPP the Pandora temperature correction has mostly removed any seasonal dependence. The small residual seasonal dependence is not statistically significant. Figure 7 shows that there is high correlation $\left(r^{2}=0.95\right)$ between OMI and NPP ozone compared with Pandora ozone measurements. The temperature-corrected Pandora TCO closely tracks the daily variations observed from OMI and NPP and has little residual seasonal dependence. It should be noted that the wavelengths for the OMTO3 discrete wavelength algorithm were selected to minimize temperature dependence.

A similar comparison between OMI and NPP is shown in Figs. 8 and 9 based on the TCO overpass data for Boulder, Colorado (see Table 4), for the year, starting 17 December 2013. The two independent retrievals of satellite TCO show reasonably good agreement even though the ground location 

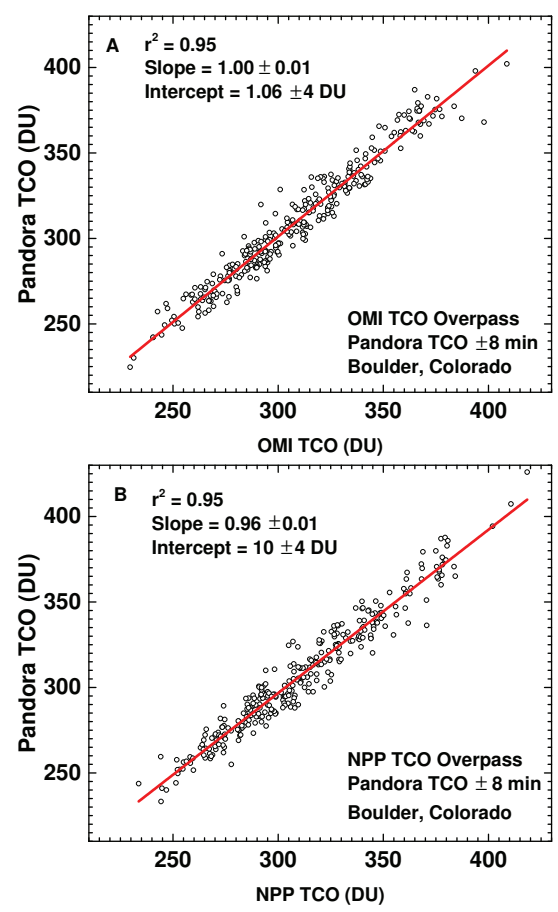

Figure 7. Scatterplot comparisons (a) between Pandora TCO measurements and those from OMI and (b) comparison with those from NPP. Shown are the correlation coefficient $r^{2}$, slope, and $y$ intercept.

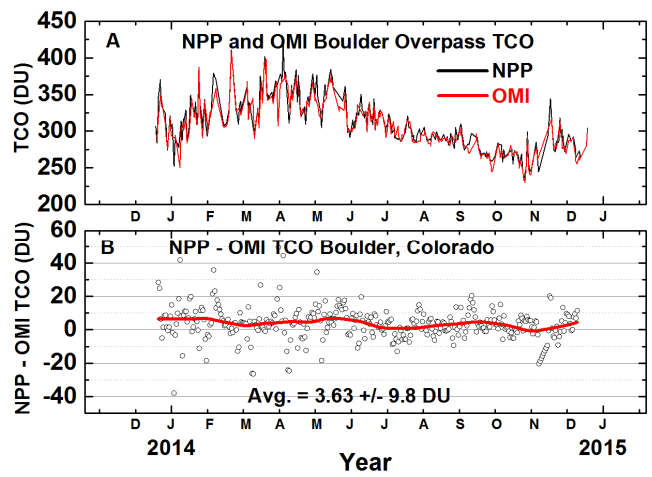

Figure 8. (a) Comparison of retrieved Boulder, Colorado, overpass TCO; (b) difference NPP - OMI TCO.

of each satellite's field of view is different by up to $50 \mathrm{~km}$ and the satellite retrievals use different $\mathrm{O}_{3}$ absorption cross sections. The correlation is given by $r^{2}=0.96$ in Fig. 9 but with a slope of 0.9 , suggesting a small bias between OMI and NPP TCO. This is also shown by the average of the difference in $\mathrm{TCO}_{\mathrm{NPP}}-\mathrm{TCO}_{\mathrm{OMI}}=3.6 \mathrm{DU}$ but with a standard deviation of $9.8 \mathrm{DU}$. Given the scatter in the points, the difference is not significant.

For the comparison of Pandora \#34 and the Dobson \#061, the TCO data were filtered for the presence of clouds using the Dobson AD-DSGQP criteria for cloud-free observa-

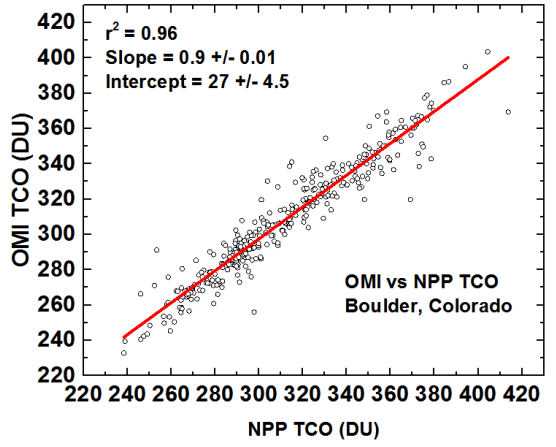

Figure 9. Scatterplot of NPP OMPS vs. AURA OMI TCO.

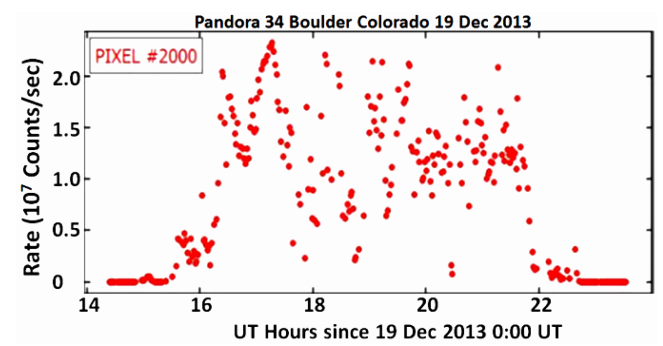

Figure 10. Pixel 2000 (about $520 \mathrm{~nm}$ ) in counts per second vs. time of day (UT) for a cloudy day (Thursday, 19 December 2013).

tions. When comparing Pandora ozone measurements with OMI and NPP, partial cloud filtering was used based on an estimate of the Pandora ozone retrieval uncertainty $(<2 \%)$ and spectral fitting residual of $<0.1$ for each measurement. In addition, 12 Pandora measurements are averaged together over \pm 8 min about the Dobson, OMI, or NPP measurement times, increasing the Pandora signal-to-noise ratio by a factor of 3. For OMI and NPP comparisons there is still residual scatter in the presence of light clouds even though the ozone retrieval is acceptable.

\section{Pandora TCO data}

The Pandora spectral data contain a clear measure of the occurrence of clouds and clear scenes during each day within its field of view, $2.2^{\circ}$ surrounding the sun, by saving the output in counts from one pixel (\# 2000) at approximately $520 \mathrm{~nm}$. Cloudy (Fig. 10) and clear (Fig. 11) situations are easily distinguished. Moderately cloudy conditions, such as depicted in Fig. 10, will reduce the spectral signal and increase the statistical retrieval error to greater than $2 \%$. In contrast, the day depicted in Fig. 11 is nearly cloud free.

The average effect of moderate cloud cover on 19 December 2013 reduced the average observed intensity at all wavelengths (by a factor of 2 at $520 \mathrm{~nm}$ ). The effect on the retrieved ozone is to increase the apparent noise level of the ozone retrieval (Fig. 12: $\mathrm{SD}=2 \mathrm{DU}$, where $\mathrm{SD}$ is the standard deviation from the mean of the difference between 


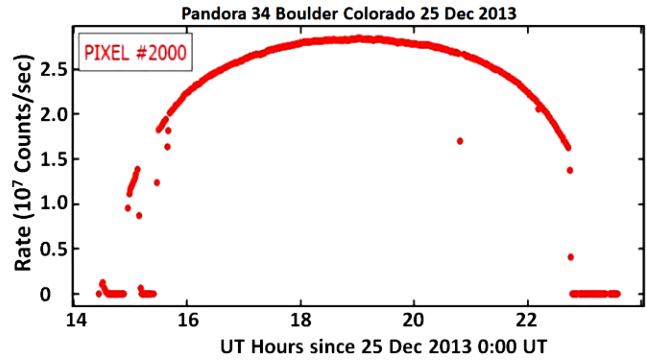

Figure 11. Pixel 2000 (about $520 \mathrm{~nm}$ ) in counts per second vs. time of day (UT) for a clear day (Wednesday 25 December 2013).

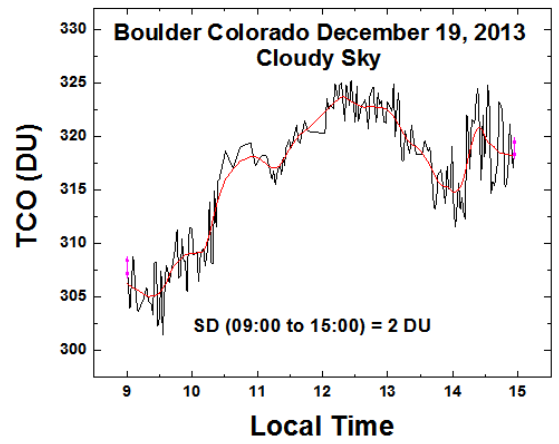

Figure 12. Pandora-retrieved TCO under cloudy conditions as shown in Fig. 7 and a Lowess(0.2) fit (red curve) to the TCO data.

the ozone data and a Lowess fit) as compared to the clearsky case (Fig. 13: $\mathrm{SD}=0.8 \mathrm{DU}$ ). For thin-cloud conditions, direct-sun observations have very few scattered photons in Pandora's $2.2^{\circ}$ FOV and negligible multiple scattering effects. The ozone retrieval for 19 December also has missing cloud-filtered data for short periods when the clouds were thick in the Pandora FOV. Data before 09:00 and after 15:00 are not reliable in December at $40^{\circ} \mathrm{N}$ because of increasing stray light effects for $\mathrm{SZA}>75^{\circ}$. For the Boulder site, there are obstructions for direct-sun observations (a building and the mountains) in the early morning and late afternoon as shown by the counts dropping to nearly 0 (Figs. 10 and 11).

All of the Pandora TCO values have had a retrieval filter applied that limits the formal retrieval noise to $2 \mathrm{DU}$ (about 0.5 to $1 \%$ error). During December, the noon SZA was about $63.5^{\circ}$. Good retrievals of TCO can be obtained up to SZA of about $75^{\circ}$, if the Pandora field of view is not obstructed. At large SZA, the spectrometer retrieval can be affected by stray light as the direct contribution of photons in the $305-320 \mathrm{~nm}$ range is diminished by the large ozone absorption AMF. For days or locations with high total column ozone values, the SZA cutoff can be smaller. The Pandora ozone spectral fitting retrieval algorithm inversely weights the contribution of each wavelength by its increased standard deviation from the mean caused by reduced count rate with increasing AMF. The effect of the effectively shifted wavelength retrievals is

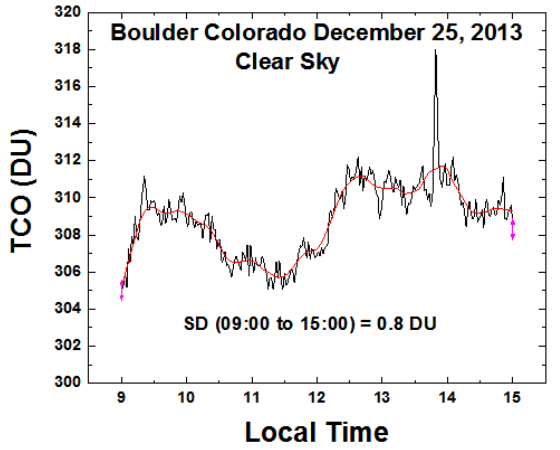

Figure 13. Pandora-retrieved TCO under clear-sky conditions as shown in Fig. 8 and a Lowess(0.2) fit (red curve) to the TCO data.

taken into account in the temperature corrections shown in Table 2 and Fig. 3.

Figure 14 shows a sample of Pandora ozone retrievals throughout 13 consecutive days. For the Boulder, Colorado, location there are substantial TCO variations during most days, which are only partially detected in the Dobson measurements obtained a few times each day. Because of this variation, the Pandora time interval selected for the PandoraDobson comparison must be kept fairly short (e.g., $\pm 8 \mathrm{~min}$ ) without causing under-sampling of the coincident time series. Note that each daily graph has a vertical axis range of $60 \mathrm{DU}$ to visually show the different daily daytime variation in retrieved TCO. Based on the set of observations, the morning to afternoon change is almost as likely to show increases or decreases over an extended range of days.

\section{Summary and conclusion}

A 1-year-long comparison (17 December 2013 to $18 \mathrm{De}$ cember 2014) between collocated and time-matched TCO derived from the Pandora \#34 and Dobson \#061 instruments (limited to clear-sky AD-DSGQP data) shows agreement with a small residual $1.1 \pm 5.8 \mathrm{DU}$ bias after correction for ozone-weighted temperature climatology appropriate for Boulder, Colorado, at $40^{\circ} \mathrm{N}$. Before the temperature correction is applied to both Pandora and Dobson ozone values, there is small ( -5 to $1 \mathrm{DU}$ ) seasonal dependence in the difference between Pandora and Dobson TCO. After the climatologically derived and total ozone-adjusted temperature correction for each instrument is applied to the retrieved TCO values, the comparisons show reduction in the seasonal bias by a factor of two. Some of the differences between the Dobson and Pandora TCO may be associated with day-to-day variability in the stratospheric ozone and temperature not accounted for in the climatological temperature data set. Comparisons of Pandora TCO with both AURA/OMI and NPP/OMPS satellite data show very good agreement for the day-to-day variations and seasonal dependence even in the presence of light to moderate cloud cover. The compar- 


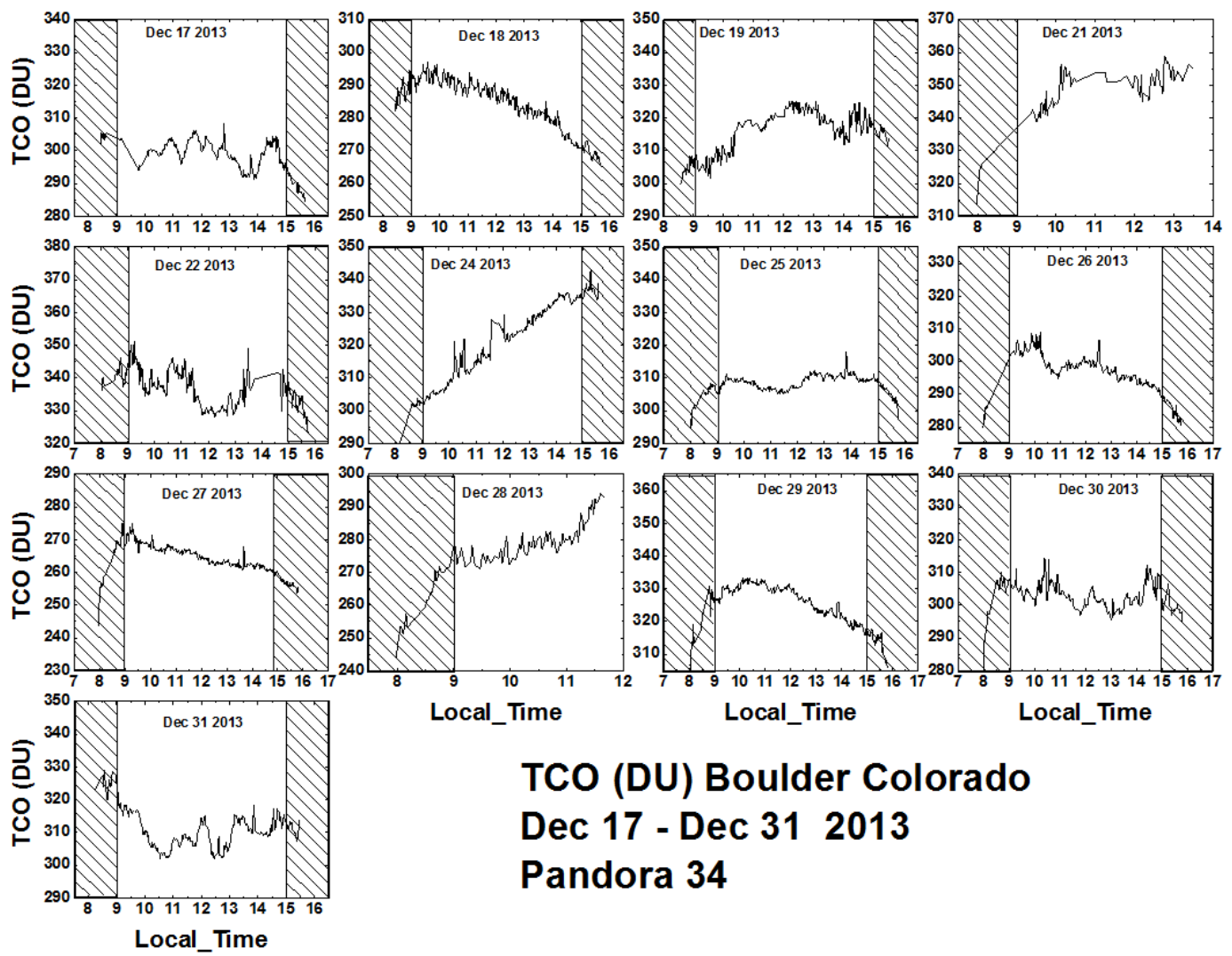

Figure 14. The variation of Pandora-retrieved TCO throughout each day in Boulder, Colorado, from 17 December 2013 to 31 December 2013. The timescale is local standard time (GMT -7). Times before 09:00 and after 15:00 are shaded. All vertical scales encompass 60 DU.

ison showed average Pandora TCO agreement with OMI to within $0.3 \%$ (1.1 DU) with $2 \%$ variability about the mean. A similar comparison with OMPS showed $1 \%$ offset (3.8 DU, OMPS > Pandora) with $2 \%$ scatter. Reprocessing the Dobson TCO retrievals using BDM ozone cross sections (see Appendix A) increased the annual average TCO by $2 \mathrm{DU}$ $(0.6 \%)$ with similar residual seasonal variation with respect to Pandora TCO retrievals. The nearly continuous Pandora TCO retrieval shows that on any given day there can be strong diurnal variation, but when averaged over 28 days the average diurnal variation is small ( $\pm 5 \mathrm{DU})$. The yearlong comparisons with the Dobson, OMI, and OMPS show that the Pandora system is stable and reliable with almost no operator intervention. The results of the Dobson comparison and a previous Brewer comparison (Tzortziou et al., 2012) suggests that the automated Pandora spectrometer system may be suitable as a replacement for older, more expensive ozone monitoring instruments with the additional benefit of Pandora also measuring other trace gas amounts. Additional comparison campaigns with Brewers and Dobson instruments will be carried out in the future. 


\section{Appendix A}

Reprocessing the Dobson data using the $\mathrm{BDM} \mathrm{O}_{3}$ cross sections increases the fixed temperature values of retrieved $\mathrm{O}_{3}$ by $0.8 \%$ relative to retrievals using Bass and Paur cross sections. The BDM temperature sensitivity is $0.042 \%{ }^{\circ} \mathrm{K}^{-1}$ or $C_{\text {Dobson-BDM }}=0.00042\left(T_{\mathrm{E}}-226.7\right)$ per ${ }^{\circ} \mathrm{K}$ (Redondas et al., 2014). When the Dobson-measured radiances are processed with the BDM ozone cross sections instead of those from Bass and Paur, the Dobson values are increased by 2 DU, but the temperature dependence for the difference between Pandora and Dobson ozone values remains the same (Fig. A1). The Pandora-measured radiances use BDM ozone cross sections to retrieve TCO.

The almost identical Lowess( 0.5$)$ curves (inset in Fig. A1) are from retrieving Dobson TCO with Bass and Paur (Fig. 3) and again with BDM cross sections. The Dobson BDMPandora TCO Lowess $(0.5)$ curve is shifted by -2 DU to give a nearly identical over plot. This is because the Pandora spectral fitting ozone retrieval algorithm has more temperature sensitivity than the Dobson pair ratio ozone retrieval method does.

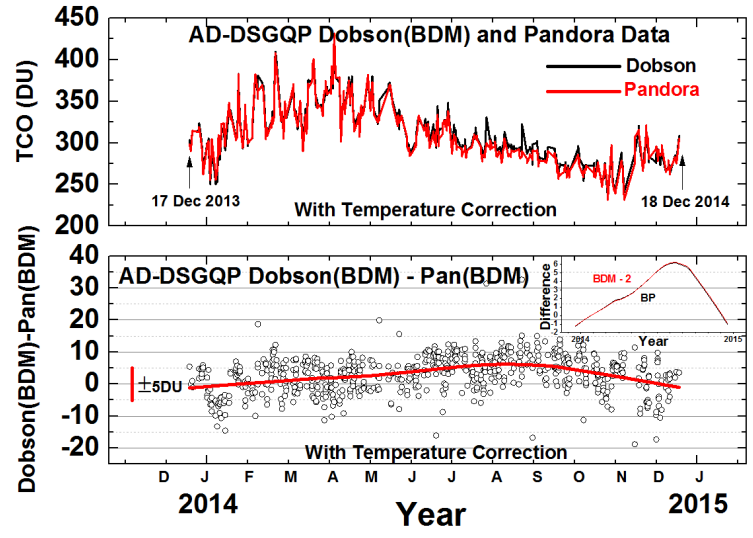

Figure A1. Temperature-corrected retrieved TCO data obtained from the Dobson \#061 instrument using the BDM ozone cross sections and Pandora \#34 spectrometer using BDM. (b) The difference TCO(Dobson) - TCO(Pandora) with temperature corrections. The standard deviation from the red Lowess curve is \pm 5 DU. Inset compares the Lowess(0.5) difference curves for Dobson with Bass and Paur cross sections for Fig. 3 (Black) with the Lowess(0.5) difference curves for BDM-2 DU (Red). 
Acknowledgements. The authors would like to acknowledge NASA's support from the DISCOVER-AQ program and NOAA for their support and use of their facilities.

Edited by: J. Staehelin

\section{References}

Bass, A. M. and Paur, R. J.: The Ultraviolet Cross-Sections of Ozone: Part I. The Measurements, edited by: Zerefos, S., Ghazi, A., and Reidel, D., Halkidiki Greece, Proceedings of the Quadrennial Ozone Symposium on Atmospheric Ozone, Norwell, 606-610, 1985.

Bernhard, G., Booth, C. R., and Ehramjian, J. C.: Version 2 data of the National Science Foundation's Ultraviolet Radiation Monitoring Network: South Pole, J. Geophys. Res., 109, D21207, doi:10.1029/2004JD004937, 2004.

Bernhard, G., Evans, R. D., Labow, G. J., and Oltmans, S. J.: Bias in Dobson total ozone measurements at high latitudes due to approximations in calculations of ozone absorption coefficients and air mass, J. Geophys. Res, 110, D10305, doi:10.1029/2004JD005559, 2005.

Bhartia, P. K. and Wellemeyer, C. W.: OMI TOMS-V8 Total O3 Algorithm, Algorithm Theoretical Baseline Document: OMI Ozone Products, edited by: Bhartia, P. K., Vol. II, ATBD-OMI-02, Version 2.0, August 2002.

Brion, J., Chakir, A., Daumont, D., Malicet, J., and Parisse, C.: High-resolution laboratory absorption cross section of O3 Temperature effect, Chem. Phys. Lett., 213, 610-612, 1993.

Brion, J., Chakir, A., Charbonnier, J., Daumont, D., Parisse, C., and Malicet, J.: Absorption spectra measurements for the ozone molecule in the 350-830 nm region, J. Atmos. Chem., 30, 291299, 1998.

Cede, A. and Herman, J.: Measurements of $\mathrm{O}_{3}, \mathrm{SO}_{2}, \mathrm{NO}_{2}$ and $\mathrm{HCHO}$ column amounts using a Brewer spectrometer Ultraviolet Ground- and Space-based Measurements, Models, and Effects V, edited by: Bernhard, G., Slusser, J. R., Herman, J. R., Gao, W., Proc. of SPIE Vol. 5886, doi:10.1117/12.620167, 2005.

Cleveland, W. S. and Devlin, S. J.: Locally-Weighted Regression: An Approach to Regression Analysis by Local Fitting, Journal of the American Statistical Association, 83, 596-610. doi:10.2307/2289282, 1988.

Dobson, G. M. B.: Observers handbook for the ozone spectrophotometer, Ann. Int. Geophys. Year, 5, 46-89, 1957.

Dobson G. M. B.: 40 Years Research on Atmospheric Ozone at Oxford - A History, Appl. Optics, 7, 387-405, doi:10.1364/AO.7.000387, 1968.

Evans, R. D. and Komhyr, W. D.: Operations Handbook - Ozone Observations with A Dobson Spectrophotometer, World Meteorological Organization Global Atmosphere Watch GAW No.183, WMO/TD-No. 1469, 2008.
Herman, J. R., Cede, A., Spinei, E., Mount, G., Tzortziou, M., and Abuhassan, N.: $\mathrm{NO}_{2}$ Column Amounts from Ground-based Pandora and MFDOAS Spectrometers using the Direct-Sun DOAS Technique: Intercomparisons and Application to OMI Validation, J. Geophys. Res., 114, D13307, doi:10.1029/2009JD011848, 2009.

Komhyr, W. D. and Evans, R. D.: Operations handbook-ozone observations with a Dobson spectrophotometer, Global Ozone Research and Monitoring Project, Rep. 183, World Meteorological Organization, Geneva, Switzerland, 91 pp., 2006.

Komhyr, W., Mateer, C., and Hudson, R.: Effective Bass-Paur 1985 Ozone Absorption Coefficients for Use With Dobson Ozone Spectrophotometers, J. Geophys. Res., 98, 20451-20465, 1993.

Langley, S. P.: Researches on solar heat and its absorption by the Earth's atmosphere. A report of the Mount Whitney Expedition, Professional Papers of the Signal Service, No. 15, Govt. Printing office, Washington, 1-242, 1884.

Malicet, J., Daumont, D., Charbonnier, J., Parisse, C., Chakir, A., and Brion, J.: Ozone UV spectroscopy. II. Absorption crosssections and temperature dependence, J. Atmos. Chem., 21, 263273, 1995.

Mateer, C. L. and DeLuisi, J. J.: A new Umkehr inversion algorithm, J. Atmos. Terr. Phys., 54, 537-556, 1992.

McPeters, R. D., Labow, G. J., and Logan, J. A.: Ozone climatological profiles for satellite retrieval algorithms, J. Geophys. Res., 112, D05308, doi:10.1029/2005JD006823, 2007.

McPeters, R. D. and Labow, G. J.: Climatology 2011: An MLS and sonde derived ozone climatology for satellite retrieval algorithms, J. Geophys. Res., 117, D10303, doi:10.1029/2011JD017006, 2012.

Redondas, A., Evans, R., Stuebi, R., Köhler, U., and Weber, M.: Evaluation of the use of five laboratory-determined ozone absorption cross sections in Brewer and Dobson retrieval algorithms, Atmos. Chem. Phys., 14, 1635-1648, doi:10.5194/acp14-1635-2014, 2014.

Shaw, G.: Genesis of sun photometry, J. Appl. Remote Sens., 1, 113, 012503, doi:10.1117/1.2712483, 2007.

Tzortziou, M., Herman, J. R., Cede, A., and Abuhassan, N.: High precision, absolute total column ozone measurements from the Pandora spectrometer system: Comparisons with data from a Brewer double monochromator and Aura OMI, J. Geophys. Res., 117, D16303, doi:10.1029/2012JD017814, 2012.

Van Hoosier, M. E.: Solar ultraviolet spectral irradiance data with increased wavelength and irradiance accuracy, SPIE Proceedings, 2831, 57-64, 1996.

Wellemeyer, C. G., Taylor, S. L., Seftor, C. J., McPeters, R. D., and Bhartia, P. K.: A correction for total ozone mapping spectrometer profile shape errors at high latitude, J. Geophys. Res., 102, 90299038, doi:10.1029/96JD03965, 1997. 